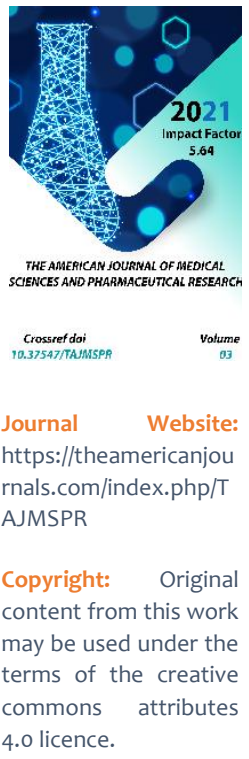

\title{
Epidemiological Picture Of Coronavirus Infection (COVID-19) In Uzbekistan
}

Ataeva Mashhura Abrarovna

Associate Professor, Head Of The Department Of Public Health And Health Care Management, Bukhara State Medical Institute, Bukhara, Uzbekistan

\section{ABSTRACT}

A study of the general increase in the incidence of the disease is currently being carried out by the epidemiological service, according to which in $95 \%$ of cases people become infected while living together or in the same house with an infected person. Among those arriving from abroad, one or two infected persons are detected every day. In 99\% of cases, the disease is found in those who have had contact with infected citizens living in Uzbekistan[1,3].

\section{KEYWORDS}

Coronavirus infection, COVID-19, epidemiology, clinic, diagnosis, Uzbekistan

\section{INTRODUCTION}

Coronaviruses are members of the large family Coronaviridae in the order Nidovirales, subfamily Cornidovirineae The first coronavirus was discovered in 1931 as Infectious Bronchitis Virus (IBV). Today, this virus is referred to as an avian coronavirus. Human coronaviruses (HCOV - HUMAN CORONAVIRUSES) were discovered in 1965[3]. Of the 7 known human coronaviruses, 4 cause only mild to moderate acute respiratory infections, and 3 are known to cause the particularly dangerous MERS-CoV, SARS-COV and SARS-CoV-2[6,15]. 


\section{MATERIALS AND METHODS}

Morphology of coronavirus virions. The enveloped viral particles have a rounded pleomorphic shape. The club-shaped surface peplomers, which form 'crown teeth' of length from the trimers of glycoprotein S. M protein is transmembrane-bound. Protein E pentamers form ion channels and are an important factor in the virulence of coronaviruses. The nucleocapsid of helical symmetry is formed by phosphorylated protein $\mathrm{N}$ in complex with genomic virion RNA[2]. COVID-19 (Corona Virus Disease 2019) is a potentially dangerous disease caused by SARS-CoV-2, which can occur as a mild acute respiratory viral infection or as a severe disease[7,9].

The natural reservoir of the SARS-CoV-2 virus is bats. An additional reservoir could be mammals eating bats, with further spread to humans. Phylogenetic studies of the isolated strains showed that the genomic sequences of the viruses found in bats were 99 per cent identical to those isolated in patients with COVID-19. According to serological and phylogenetic analyses, coronaviruses are divided into three genera: alphacoronavirus, betacoronavirus and gamma coronavirus. The natural hosts of most of the currently known coronaviruses are mammals [2,4,14]. Currently, the main source of infection is a sick person, including those in the incubation period of the disease.

The acute period of infection with coronavirus in patients lasts on average 18-19 days. It has been observed that the acute phase of the disease can last from 11 days to 28 days, but the SARS-COV-2 virus will only survive for 11 days, and the recovery period may take up to several months. Duration of illness" refers to the duration of the acute period of infection, including the period from the onset of the first symptoms until the acute manifestations of COVID-19 have resolved, as well as the length of the recovery period, which may take up to several months[1,5,15]. Transmission is through the airborne route (coughing, sneezing, talking). The contact route occurs through transmission factors: water, foodstuff and objects contaminated with the pathogen. There is a proven risk of transmission from hands to the mucous membranes of the eyes, nose and mouth, and disease. A faecal-oral mechanism is possible (the pathogen has been detected in faecal samples from patients infected with SARS-(oV-2), but evidence to date[4,16].

Risk groups for severe disease and risk of death: - People over 60 years of age; - Patients with chronic diseases (diabetes, respiratory diseases, cardiovascular diseases, cancer). Virus excretion from the patient is maximal during the first 1-3 days of illness and can start up to 48 hours before onset Virus can be isolated from faeces but there is no evidence yet of a faecal-oral transmission mechanism Virus excretion usually lasts for up to 12 days in mild/moderate cases and $>2$ weeks in severe cases. In patients who have recovered, PCR may be positive after symptoms have disappeared. There is no significant circulation of the virus in the population (0.14\% of 320000 persons tested)[3,17]. The vast majority of infections arise from contact with clinically manifest cases (1-5\% of 38000 close contacts develop (OVID-19) Most transmission occurs in familial clusters (75-85\% of clusters). The recent emergence of COVID-19 means that understanding of transmission patterns, severity, clinical features and risk factors for infection remains limited, both in the general population, for health care workers, and in- 
home and other "closed" settings. Research to assess the epidemiology and clinical characteristics of cases in different settings is therefore crucial to advancing our understanding of the virus and associated disease. They will also provide the reliable information needed to refine the parameters to be used in prediction models. The global public health community has recognized the need for standardized research and data collection following outbreaks of highly pathogenic avian influenza subtype $\mathrm{H}_{5} \mathrm{~N} 1$ and during the $\mathrm{H}_{1} \mathrm{~N}_{1}$ influenza pandemic in 2009. Since 2011, two international and highly representative networks (ISARIC and CONCISE) have been working to standardize clinical, epidemiological and laboratory methods to be used during outbreaks. A WHO expert working group on pandemic influenza special studies and research has developed several standard protocols for influenza. Similar protocols were developed by WHO, in collaboration with technical partners for Middle East respiratory syndrome coronavirus (MERS-CoV)[5,6]. With support from expert consultants, WHO has now adapted influenza and MERS-CoV protocols to improve understanding of the clinical, epidemiological and virological characteristics of COVID-19. Coronavirus as of 22 July 2021, the number of reported cases of COVID-19 infection is 122,048 $(+719)$. The number of deaths due to the disease has reached 814 . As of 22 July 2021, the number of reported cases of COVID-19 infection is 122,048 (+719). The number of deaths from the disease has reached 814 . The incidence of the coronavirus infection has been increasing daily since June 10-12, Botir Kurbonov, deputy head of the Republic Sanitary and Epidemiological Surveillance and Public Health Service, said. However, this does not mean that the epidemiological picture in the republic is critical, the epidemiologist added." I can't say that the situation is very complicated because, in neighbouring countries, such as Russia, Kazakhstan and other neighbouring republics, including Afghanistan, the epidemiological situation remains a bit more complicated than in Uzbekistan" [2]. According to the Ministry of Health, as of 22 July 2021, the number of registered cases of infection with coronavirus is $122,048(+719)$. The number of deaths due to the disease has reached 814 . In addition, he explained that the main reason why patients die is that they do not seek medical help in time. In addition, many of them have chronic diseases and are self-medicating, the doctor noted $[13,18]$.

\section{CONCLUSION}

Thus, most new cases of COVID-19 infection are established in large cities and densely populated areas. In particular, in Tashkent, more than 100 people fall ill with the coronavirus every day, but there are also many such cases in the Tashkent region bordering the capital. In the past 24 hours, 742 cases of the new-type coronavirus infection (COVID-19) were reported in Uzbekistan, with 157,136 cases, CentralAsia (UZ) reported, citing the Health Ministry press office. Six patients diagnosed with the coronavirus died during the day, bringing the total number of fatalities caused by the dangerous infection to 1,088 . In Uzbekistan, 149,273 people recovered from the coronavirus infection, including 683 in the past 24 hours with a 95 per cent recovery rate.

\section{REFERENCES}

1. Ismoilov, O. I., Murodkosimov, S. M., Kamalova, M. I., Turaev, A. Y., \& Mahmudova, S. K. (2021). The Spread Of SARS-Cov-2 Coronavirus In 
Uzbekistan And Current Response Measures. The American Journal of Medical Sciences and Pharmaceutical Research, 3(03), 45-50.

2. Assessment of the preparedness of health facilities to prevent the introduction and spread of infectious diseases posing a sanitary and epidemiological emergency. A training manual for doctors. Moscow, 2017. Ser. Library of the All-Russian Disaster Medicine Service.

3. Nikiforov V.V., Suranova T.G., Orlova N.V., Kardonova E.V., Smetanina S.V. (2019). Algorithms of medical care for patients with acute respiratory infections. Modern polyclinic. Medical alphabet. 2(27) (402). 6-13.4.

4. Decree of the Chief State Sanitary Doctor of the Republic of Uzbekistan No. 3 "On improvement of additional preventive and anti-epidemic measures to prevent penetration and spread of coronavirus infection on the territory of the Republic of Uzbekistan". (27.02.2020).

5. Decree of the President of the Republic of Uzbekistan on measures to ensure more effective organisation of acquiring rights to land plots and other immovable property as part of the South Caucasus gas pipeline expansion project (27.02.2020).

6. Prevention, Diagnosis and Treatment of New Coronavirus Infection (2019nCoV) Current Guidelines. Moscow, 2019.

7. Order of the Minister of Health of the Republic of Uzbekistan No 176 "On improvement of anti-epidemic measures in the treatment of patients with coronavirus infection and prevention of the spread of the disease" of 2 July 2020.

8. Konradi, A. O., \& Nedoshivin, A. O. (2020). Angiotensin II and COVID-19. Secrets of interactions. Russian Journal of Cardiology, 25(4), 3861.,

9. Interim guidelines "Prevention, diagnosis and treatment of new coronavirus infection (COVID-19). Version 9" (approved by the Ministry of Health of the Russian Federation on October 26, 2020).

10. V.A. Zinserling1, M.A. Vashukova, M.V. Vasilyeva, A.N. Isakov, N.A. Lugovskaya, T.A. Narkevich, U.V. Sukhanova, N.Y. Semenova, D.A. Gusev. Issues of pathomorphogenesis of new coronavirus infection (COVID19)". Jurnal Infektologii.

11. Nikiforov VV, SuranovaTG, Mironov TY, Zabozlaev FG. (2020). A new coronavirus infection (COVID-19): etiology, epidemiology, clinic, diagnosis, treatment and prevention. Moscow. P.48.

12. Zairatjants O.V., Samsonova M. V., Mikhaleva L.M., Chernyaev A.L., Mishnev O.D., Krupnov N.M., Kalinin D. V. (2020). Pathological anatomy COVID19: Atlas. Under the editorship of O.V. Zairatyanets. Moscow, NIIOZM DZM, $140 \mathrm{p}$.

13. O.S. Kobyakova, I.A. Deev, E.S. Kulikov, I.D. Pimenov, K.V. Khomyakov, (2016). Emotional burnout in doctors and medical errors. Is there a connection? Social aspects of public health. No.1. pp.1-13.

14. Akindinova I.A., Bakanova A.A. Emotional burnout in the professional activity of a teacher: manifestations and prevention / I.A. Akindimova, A.A. 
Bakanova // Pedagogical news. - SPb.:

Publishing house of Russian State Pedagogical university n.a. A.I. Gertsen, 2003. - №5. - C. 34.

15. Samokhvalov, N. Krylov, D. Vychuzhanin. (2017). Emotional burnout syndrome in physicians (how many years do I have left?). Phys. No.9. pp. 2-5.

16. Vodopyanova N.E. (2000). Mental burnout syndrome in communicative professions. Psychology of Health [Edited by G.S. Nikiforov]. SPb.: Publishing house of SPbSU. pp.443463.

17. Vodopyanova N.E. (2002). Mental burnout. Dentist. Moscow. Medicina. No.7. p.12.

18. Zakharov, I.A. Uvarov, G.R. Ivanova. (2018). Emotional burnout syndrome and how to fight it. Medical nurse. No.1. pp.36-38. 